\title{
Realities on the Ground: Sampling Process and Methodology
}

The context and direction for this study was guided by the premise that storekeepers are important figures in neighborhood life, from which the three sets of sensitizing concepts were derived to help set the context and direction for my study. I combine the concepts of public characters and third place and use the nexus between them. It is often public characters, or owners, that perform "public character practices" to a certain extent, and who operate third places. But not all owners of third places act as public characters, nor do all public characters necessarily operate businesses that serve as third places. However, these concepts provide an analytic frame and serve as a point of reference as well as a guide in the analysis of data and, in particular, in the selection of the cases (cf. Bowen 2006; Glaser/ Strauss 2009).

\subsection{Theoretical Sampling}

Theoretical sampling lies at the core of developing a "grounded theory": Essentially, the credibility of a theory cannot be dissociated from the process by which it has been generated (Glaser/ Strauss 1967; Strauss/ Corbin 1998). The term "grounded" stems from grounded in the data from which it was derived, insofar as the sampling process has a "theoretical" orientation and is directed towards the generation and development of a conceptual theory. In this case, theory is gradually derived from the data and the data's recourse to the mentioned theoretical concepts of third 
place/ public character, community building and (semi-) public interaction. In the course of the inquiry the emerging theory progressively focuses the data collection in order to refine and integrate the theory (Glaser/ Strauss 1967). I am aware that Glaser and Strauss's approaches differ widely. For the sake of this research, their ideas are rather treated as a set of tools and approaches to ground an emerging theory in empirical data, gained through interviews and observations. However, I systematically follow their elaborations on a theory driven sampling process, which can be broken down into stages of open sampling, relational, and variational sampling, as well as discriminate sampling (Strauss/ Corbin 1998, suggesting a different way of data processing), which correspond directly to their stages of open, axial, and selective coding (Glaser/ Strauss 1967). Axial coding involves the application of a so-called coding paradigm in order to identify conditions, context, action/interactional strategies, intervening conditions, and consequences. For this reason I apply for each code the questions of why, where, who, how, what, for what and under what conditions.

Barney Glaser and Anselm Strauss (1967: 45; 2009) originally defined theoretical sampling as

the process of data collection for generating theory whereby the analyst jointly collects, codes and analyses his data and decides what data to collect next and where to find them, in order to develop his theory as it emerges.

Hence, the aim is to discover a maximum number of variations among concepts and to densify categories in terms of their properties and dimensions.

The theoretical sampling process begins with an initial data collection and analysis. The open coding of raw data generates first codes that in turn stimulate the ongoing data collection. In the early stages of analysis, codes are rapidly generated. By means of a joint process of theoretical sampling and memo writing, codes are corrected and edited, as well as continually adjusted to the data. Memo writing enables the conceptualization of each category's boundaries and properties and points to potential gaps in the emerging theory, and thus highlights where (and what) to sample next and for what theoretical purpose (Glaser 1978). The continual comparison of codes generates a further set of conceptual categories, from which in turn new categories emerge. Continuously new incidents are adjusted and readjusted into existing categories.

Accordingly, the very first business was selected on the basis of the sensitizing considerations of daily life and its respective commercial spaces of everyday supply, and then in a second step therein, on everyday social practices that might contribute to the creation of "home," "belonging," and "community" (as a space, as feelings, as 
practices). In that selection, the first guiding concept was Oldenburg's idea of third places, while maintaining a critical distance to its very narrow definition of third place characteristics and Oldenburg's emphasis on gastronomic facilities versus local amenities more generally. Further, a review of the literature on Jacobs' notion of the public character (such as well-established shopkeepers and barkeepers) lead me to question both authors' quite narrow, unsystematic, and piecemeal sample cases to prove their claims.

Consequently, I searched for an initial case that was ostensibly outside the bounds of both Oldenburg and Jacobs' assigned characteristics. On the basis of their work, my guiding consideration was to wonder if the residents - who actually and regularly shop and consume in their local surroundings - might name completely different places with different types of ownership than those that fit into Oldenburg's and Jacobs' typology. The guiding thought was that there were likely to be differences but also similarities between the academically ascribed third places and public characters and the locals' own use and ideas about these places and their business owners. These could also comprise places that were not small and individually owned businesses, but locations such as public benches, parks, libraries, self-made third places, franchise or chain stores, or even entire shopping malls (Manuel/ Thompson n.v.:2). During the search for an appropriate first field entry case, I increasingly began to question Jacobs' and Oldenburg's typology after witnessing its increased application as a (self-attributed) marketing tool of the store owners. ${ }^{95}$ For the first case selection, I nevertheless used the lack of a "classic" third place in combination with the lack or presence of public character attributes (e.g. shopkeeper's long-term presence, the performance of caring, support and generally attentive practices, local knowledge and local social networks) as the main selection criteria.

As the sampling process moved toward more contrasting cases, I used the presence of features such as playfulness, the presence of regulars, easy access, "lower" prices, and type of shopkeepers, as further selection criteria - all of which, of course, were constructed very subjectively on the basis of my local knowledge and perception. These initial conceptualizations helped me make sense of the data, but also design a clear procedure for selecting further cases. Upon beginning the analysis, I then identified the conditions, context, action/interactional strategies, intervening conditions, and consequences for each emerging theme.

95 Particularly in the US, where for instance 'third place' is more commonly used and where increasingly more businesses, housing and community developers recognize the role of third places for their goals. But also, businesspeople promote their stores by using references to the local community and the important role of local economy in Germany. 


\subsection{Sampling Process}

After a literature review on the street's development, but before I started the search for a first case study, I conducted an exploratory expert interview with the head of the local planning agency in order to gain a better understanding of past developments as well as of the current status of Karl-Marx-Straße's commercial structure. This expert interview also served as the very first field site entry contact. The planning office acts as City Management, supervising the development of the street's trade, by means of its own institutional expertise garnered through interviews, surveys, and studies on the local commercial structure and relationships with long-term and newer local businesspeople. ${ }^{96}$ In this interview, I planned to ask about shop owners that are particularly strongly linked, engaged, and socially rooted in the street and hence could potentially be considered public characters (from the perspective of the expert).

Before I had even begun to ask my questions about potential public characters among the shopkeepers on Karl-Marx-Straße, the interviewed urban planner mentioned - to my surprise - a long-standing and individually owned, but very small, flower shop. The urban planner's recommendation to visit this store in particular, since the owner had a deep well of local knowledge, startled me since flower shops do not necessarily fit to Oldenburg's typologies of a third place, insofar as it is an uncomfortably cold place, without the space for socializing, and the vegetation on offer cannot be classified as part of daily supply. However, the way the owner's network was described fit into Jacobs' definition of the public character. Based on this interview, I began my empirical fieldwork by approaching this store, despite the fact that on my own local knowledge would have suggested a different set of stores. I also decided to examine this business as my first case study, because after numerous unsuccessful attempts at contacting the other stores along Karl-Marx-Straße (defined roughly as those between the two subway stations), the flower store owner was the first to respond positively to my request for an interview. Unexpectedly, and despite the chilliness and lack of space to "hang out," the tiny flower store and its owner serve as an extended living room for the longstanding elderly residents from the surrounding buildings. ${ }^{97}$

96 For further information see Aktion! Karl-Marx-Straße (n.d.). Citymanagement der [Aktion! Karl-Marx-Straße], http://www.aktion-kms.de/akms/ansprechpartner/citymanagement-der-aktion-karl-marx-strasse/, accessed 03/10/2016.

97 My first interview and subsequent observations revealed that these customers depend strongly not only on the flower store, but also on other, very local amenities, since most of them are unable to cover more the distance of a block on foot. In short, their circumscribed life world and the majority of their social interactions are deeply linked 
However, after linking back the collected data on this first business case to the theoretical concepts of third place, community and particularly public interaction, concerns about the high homogeneity in terms of gender, class and ethnicity led to the selection of a second case that hosts a more diverse clientele and maybe contrasts the first case's public character and third place attributes.

With this experience in hand, I then looked for a second business that served a broader clientele, where different degrees of public or private behavior were displayed and where different age, lifestyle, and income groups could be found. I ultimately encountered a restaurant, used mainly by price-conscious local workers and businesspeople, but also tourists and shoppers, for lunch, which also catered to a gourmet-oriented city-wide clientele on specific event evenings.

From this second business (always returning to the research question and the sensitizing concepts), the sample gradually grew to encompass an ever-widening spectrum of business types (including design and size), and customer and salespeople characteristics. I also conducted observation in the local shopping mall as well as more corporate chain stores in order to discover processes and practices that contribute to community building and a sense of belonging in these rather standardized spaces; however, the core sample includes only individually owned and owner-operated businesses. Hence, I sampled both for theoretical similarity and difference in regard to third place/public character, public behavior, and community building, in order to illustrate the properties of each category, and to saturate all categories until finally a core category emerged (Glaser/ Strauss 1967).

On the one hand, the sample was also supposed to mirror the current commercial structure of the street in terms of branches, ownership, and appeal, but on the other, the sample was supposed to offer a maximum of variations within and across already existing categories, while also allowing for the potential inclusion of new concepts. Unfortunately, most business people declined to take part in the study, despite numerous attempts to contact and convince them. ${ }^{98}$

to the flower store and its owner, and as such, the shop does act as a third space, and the owner as a public character.

98 After making an initial list of all businesses between the two subway stops Rathaus Neukölln and Karl-Marx-Straße and categorizing them into branch and length of business residence, I sent out emails and parallel formal letters to at least two businesses within each branch, asking for their participation in the study, or an interview. Due to an overall weak response rate, I then called the businesses, and also walked into many of the sampled businesses and tried to convince the business owners and salespeople face-to-face. The high reluctance and opposition of the street's business people crystalized in accusations of being a "spy" for competing businesses or the local authorities (particularly the tax office), or of researching the competition before opening my own 
The initial problems in finding interview partners and potential cases mirror the concern about when to stop data collection. Because of the inductive nature of theory generation, the theoretical sampling should come to a point at which sampling will cease, controlled by the emerging and increasingly more consistent theory. Put in other words, Glaser and Strauss $(1967 ; 2009)$ consider the theoretical sampling as finished when a point of theoretical saturation has been reached - when categories and their properties are considered as sufficiently dense and when the data collection no longer generates new derivations. The point of theoretical saturation does not imply that everything is known, since theoretical sampling does not aim for a fully descriptive coverage of the data, but that enough data has been collected that the developed categories not only have high explanatory value, but also integrate the core variables grounding the emerging theory. My greatest concern was not when to stop collecting case studies, but rather when to end observations in the already sampled and "interviewed" cases, since most of the field site visits still revealed new aspects and new variations of already identified themes.

The resulting case studies have played a decisive role in Karl-Marx-Straße' transformation over the late twentieth and early twenty-first century, mostly hidden from the view of dominant society and local politicians and authorities. They have been at the forefront of urban change, increasingly satisfying gentrifiers' tastes for ethnic and social diversity (Zukin 1987), despite having contributed for decades to the area's diversity of social, commercial, and cultural practices. Many struggle to keep their businesses alive, and experienced financial losses due to the current reconstruction of the street. Along with the long working hours required of owners of small independent owned stores, I acknowledge the business people's high level of skepticism and distrust in talking to me. This is why I am particularly grateful to those - even if fewer than planned - owners who introduced me to and included me in the small life worlds of their businesses.

business. Many of the participating business people still tested my local knowledge and my intentions in the meetings and interviews. I assume that this high level of skepticism and suspicion stemmed from the heightened business competition, the increasingly authoritative and controlling or even exclusionary behavior of the local authorities in the course of local urban renewal, the overall fear of neighborhood change, and previous negative experiences with local authorities and "researchers." Some mentioned (with shame) that they are struggling to survive and therefore were too busy to meet with me. On the phone many shopkeepers also asked for help, but still rejected my offer to meet with them during opening hours. 


\subsection{The Core Sample}

The core sample (defined as those businesses that generated the most material, in terms of participant observation protocols, other type of field notes and in-depth interviews) of businesses on Karl-Marx-Straße's main strip comprises

- A long standing ${ }^{99}$ flower store, owned by a woman of German descent

- A newer "German food" 100 lunch restaurant, owned by a man of German descent

- A long-standing café/bar/restaurant, named café I, owned by a man of Turkish descent

- A long-standing café/bar/restaurant, named café II, owned by a man of German descent

- A long-standing pharmacy, owned by a woman of German descent

- A long-standing butcher shop, offering lunch, owned by a man of German descent

- A newer "Turkish" café and bakery, owned by two men of Turkish descent

- A new organic grocery store, owned by two women, one of German, one of Polish descent

These seven are discussed with a focus on their spatial and social qualities in Chapter 5 along with a summary of extra cases. The core sample consists of two types of businesses broadly defined - those that necessitate a longer stay or greater need for advice, and those that are associated with a straight exchange of goods (retail, (non-gastronomic service providers). The latter type of businesses also offer professional advice, but to a lesser degree. Other businesses where I spent a significant amount of time and talked to customers and salespeople, but not in a systematic and recorded way, and thus do not form part of the core sample, are:

- A long-standing bar that closed permanently during the course of my field work, owned by a woman of Hungarian descent

- A new "hip" café, owned by a man of Turkish descent

- A long-standing fruit and vegetable store, that closed permanently during my field work, owned by a woman of German descent

99 I categorize "long standing" as more than ten years, "newer" as more than five years and "new" as less than four years of business residence (despite the fact that the sampled new businesses' length of residence is less than two years) (effective March 2016). The concrete opening dates are also mentioned in the detailed case descriptions in Chapter 5.

100 The second and seventh case businesses offer so-called ethnic cuisine, whereas the other gastronomic facilities have a less clear ethnic menu. 
- A long-standing hair salon, owned by a woman of German descent ${ }^{101}$

- A long-standing beer garden/restaurant, owned by a man of Italian descent

- A long-standing kebab take-away, unclear ownership

- A long-standing chain drug store

- A long-standing shopping mall hosting mostly new franchise stores

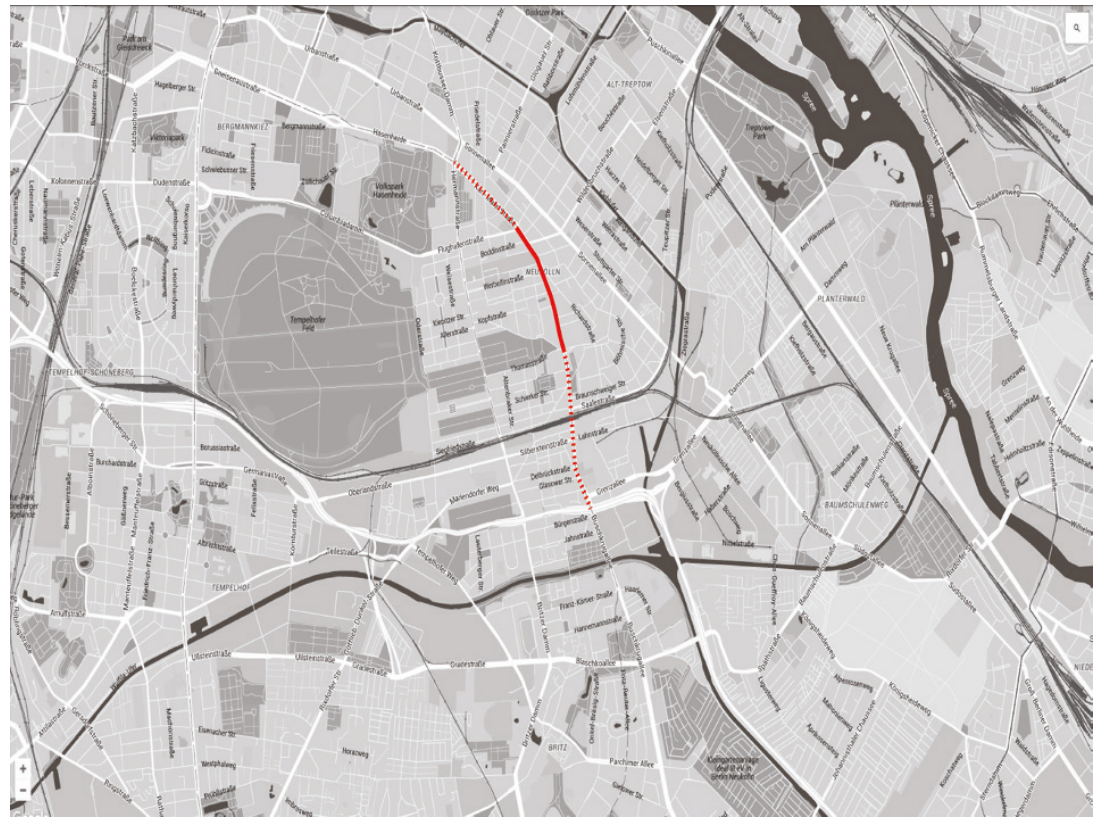

Fig. 15 Businesses' main locations along Karl-Marx-Straße

Since very little has been written on interactions between differently stratified urban dwellers in the (semi-) public spaces of businesses in German cities, the sample also focuses on business spaces where an ethnically, demographically, and socially diverse clientele shops and consumes. The existing literature mostly focuses

101 The owner agreed to an interview, but only by telephone. In the course of the conversations, she mentioned the difficult business situation and shame as the reason for her withdrawal from an in-person interview. This business welcomed predominantly elderly residents and was afraid of losing its clientele due to demographic changes (also caused by gentrification). 
on the mapping of so-called ethnic businesses (with owners, salespeople, and customers most often of Turkish descent) and their economic contribution, but almost nothing has been said about the social and cultural dynamics and contributions of multi-ethnic neighborhoods, shopping streets, and their "remarkable, yet often invisible and unrecognized contributions to urban cultures and economies" (Kuppinger 2014: 141) and social life. The studied businesses operated by an owner with a migration background are not defined as ethnic businesses in this research, as their entanglement with family and community networks is no different from their "ethnic German" counterparts. In addition, I avoid the term ethnic entrepreneur or ethnic business, since with the exception of the urban renewal program actors, none of the interview partners described themselves, or their own and anyone else's businesses in that way. ${ }^{102}$

With the core sample, I thus focus more on small and "ordinary" (Hall 2012) businesses, due to my early assumption that they also accommodate more "minute cross cultural encounters which are crucial for the creation of inclusive urban cultures" (Kuppinger 2014: 141) than their more expensive, lifestyle-oriented, and branded chain store counterparts. With the exception of the main café, the businesses that are not owned by so-called ethnic Germans belong to second-generation immigrants. In contrast to the first Neukölln generation of business-owners, who focused exclusively on the import of so-called ethnic products (particularly foodstuffs, religious goods, and clothing) for the immigrant market (e.g. Halal meat for Turkish migrants, but which was then also purchased by non-Turkish Muslim families) and filled not only a commercial niche but also the many vacant business spaces along the street, today's second (and third) generation immigrant owners have a keen understanding of their surrounding socio-spatial environment, the respective residential and customer composition, and the neighborhood's and consumption dynamics. In this context, they know that in order to survive economically on the street with its increasing rents and changing shopping patterns, they need to expand their offerings and services to the biggest possible population group and thus serve a multi-ethnic and highly diverse clientele. For this reason,

102 Just as with all small and/or individually owned businesses, so-called ethnic entrepreneurship is rooted in a structural context or state regulatory regime, as well as in resources and support mechanisms derived from the entrepreneur's social networks, which, at least in this case, are not ethnically specific, but rather mediated by class relations. In the vein of Kloostermann et al. (1999) and the businesses' "mixed embeddedness," I also rail against the reduction of "immigrant entrepreneurship to an ethnic phenomenon within an economic and institutional vacuum." Just as all business people do, immigrant entrepreneurs rely on social networks and draw on family support if needed, particularly in situations of heightened capitalistic competition or other economic issues. 
they also work much more than chain stores or lifestyle stores and their predecessors as so-called cultural brokers or "middlemen"103 (Bonacich 1973), who bridge local cultural and social gaps (Kuppinger 2014: 148).

To summarize, having begun this process with the flower shop because of its pre-ascribed role as a public character (although its physical or social features did not necessarily that hint at a third place), the second business (the lunch restaurant) was selected because first observations therein revealed higher levels of public sociability, (semi)-public behavior, and therewith third place attributes (in particular more space and seating facilities to spend time in the business and potentially socialize), but even if the owner acted less as a public character. The third case study, the additional café I (that is also a bar and restaurant), sought to capture a more classic third place in the sense that the exploratory observed business operations and seating facilities seemed to foster public sociability and interaction.

Focusing on the emerging themes in the interviews and observations, the third case study also provided a more ethnically diverse clientele, both in terms of ownership and customers. The main themes after these three cases coalesced around urban community building (but with insufficient knowledge of the participants and their selection), urban renewal as challenging the business survival and community practices, and discrimination (for both sides - person discriminating, and the individual being discriminated against). Thus for the fourth case, I searched for a minimally contrasting option, convincing the owner of the adjacent café II to talk to me and to conduct observations in the business. Whereas the clientele was as diverse as in the previous café, the majority of customers' overall consumption patterns and physical appearances hinted at a higher socio-economic background than in the three previous cases. Here, on-site observations revealed that interactions between staff and customers and among customers crossed a greater number of class and milieu lines than elsewhere. In both café/bar/restaurants, urban renewal seemed to be a less important theme (at least in terms of how often it was mentioned by owners and their staff), but this is not unexpected, since gentrification brought many of the newer customers to these businesses in the first place.

In order to include a more "rationalized" and less "hang out" space, the fifth case is a local pharmacy, where seating is restricted to one or two customers who need to rest, conversations are in a low tone and the atmosphere less "social." This

103 As per Bonacich (1973: 583), the principal peculiarities of these middlemen are "the economic role they play. In contrast to most ethnic minorities, they occupy an intermediate rather than low-status position. They tend to concentrate in certain occupations, notably trade and commerce [...] They play the role of middleman between producer and consumer, employer and employee, owner and renter, elite and masses." 
case was selected on the available theory but also on observation-driven assumptions that pharmacies both provide substantial and comprehensive consultation and service (therefore supporting public interaction). A further assumption was that they are places that are routinely integrated into everyday life - especially for the elderly - and that as such, they are also affected by urban renewal as well as a change in demographics. The second guiding assumption was that people do not spend more time than necessary in a pharmacy due to its highly professional or technical atmosphere, distanced conversations, and a setting full of references to disease and illness. However, because of the (often very intimate) found conversational topics, I deduced that the salespeople might have formed a trusted network at least with their regular customers, as well as with local doctors and other related medical institutions, and thus might act as public characters to a certain degree.

Since the previous cases were all more or less long-standing institutions, the fifth case was supposed to be a business that had opened only recently, where the relationship to customers and neighborhood might still be limited and the business space did not show the same level of routine practices by either employees or customers. Hence, the new organic grocery store represented the next business, combining seating facilities (for its lunch and coffee offerings) with third place features such as daily supply. Daily supply was also the focus for the selection of the subsequent case, a local butcher, which whose consumers were expected to be less conspicuous or less "conscious" than in the organic store, and, because of the refrigerated products, a very local clientele. Since the butcher's shop showed surprisingly high levels of public sociability among a surprisingly regular and surprisingly diverse and sociable crowd of customers, despite its physically uncomfortable environment (cold and bloody), the last case in the core sample was included to emphasize a more classic third place type of business, a bakery that also functions as a café. Throughout the sampling process, I also participated at business owner and community meetings, conducted observations in other chain or franchise stores, the shopping mall and individually owned businesses along Karl-Marx-Straße in order to get a fuller picture of the current commercial and ownership structure, its past and current development, but also to recruit potential interview partners and business cases for further observation.

The portraits of the selected cases' social and material space in chapter 5 convey a first but lasting impression of the history, design, appeal, and atmosphere of the business space, the character, personality and operational style of the owner and the employees, as well as the regular and random customers. These portraits form the basis for the first conceptual ideas about the core sample's social life and daily rhythms, as well as about the spatial and social variables that foster or prevent sociability and public familiarity in the stores and/or hint to the businesses' roles for 
the street and/or certain customers, before the core analysis began. These portraits were based on both the insights from the in-depth interviews with the owners, chats with employees and some customers, as well as numerous participant and non-participant observations in, and in front of, the businesses.

\subsection{Methodology}

In order to process the identified samples, their significance, as well as the consequences of social interactions and other social practices that occur around shopping locally, Grounded Theory Method (GTM) was chosen, for its empirically justified, conceptually compressed and internally-consistent theory generation. As a qualitative urban study, this research design focuses on the empirical inquiry - systematically collecting and interpreting social facts or factual findings (Atteslander 2006; 2008). The aim is to describe social phenomena and to make statements on correlations between different phenomena und possibly to test these statements or claims. Ideally, qualitative social research ideally aims to acknowledge and understand phenomena of human experience in a holistic and integrated way and from within (subjective). Finally, qualitative research aims to generate hypotheses or theories at the end of the process (Friedrichs 1990). In order to develop theoretical constructs for the respective phenomena at hand, qualitative social research often uses open and non-standardized methods of inquiry, as well as interpretative evaluation and analysis methods.

Qualitative social research typically begins with a rather imprecise research question (see Chapter 1.2.), but is then guided and sharpened by the sensitizing concepts (see Chapter 3), and by the step-by-step acquired empirical data and findings - always cycled through the lens of the sensitizing concepts, theoretical concepts, and emerging theoretical ideas. The entire process of data collection is characterized by a high degree of openness, whereby the researcher is in the field, in close proximity to the research subject. This approach also undergirds the decision for a social life world approach (defined in Chapter 4.4.1.), interwoven with a more GTM-driven sampling, inquiry, and analysis. By combining these two approaches, this research hopes to bridge the current lack of a theoretical understanding of the role of small businesses in the local social life (cf. e.g. Lofland 1998). Field work was thus aimed at the generation of a theory that describes and explains - as closely and densely as possible - the interactions and social processes in and around the local shops and eateries, the role of the social (owners) and material (businesses' 
socio-spatial setting) aspects, and the effect of these socio-spatial practices on local social life on Karl-Marx-Straße.

In the remainder of this chapter, I will first explain the decision to base the ensuing theoretical concepts in the empirically acquired data, and for deploying social life worlds as the methodological framework, before presenting the concrete forms and types of inquiry utilized, a discussion of the respective methodological and practical challenges of being in the field and having such a close proximity to research subjects, and finally, a description of the design of the data analysis.

\subsubsection{Working on the Ground: Grounded Theory Method and Small Social Life Worlds}

Instead of implementing the Grounded Theory Method (GTM) approach as a fixed method with fixed rules, Anselm Strauss' and Barney Glaser's development of grounded theory as a collection of proposals for the elaboration of a "theory founded in empirical data" (Strübing 2008: 13). Particularly their suggestions for "theoretical sampling" (primarily in the initial selection of cases and interviewees), coding, and the analysis of the collected empirical data, as well as their suggested focus on "core concepts" and the production of systematic relationships between the phenomena offer a useful framework for the empirical investigation inherent to this project. GTM generates a theory by systematically obtaining and analyzing data, and then generating patterns or "categories." From these patterns, conceptual categories or "core concepts" are developed to represent the theoretical framework's components (Glaser/ Strauss 1998). The GTM approach develops an empirically based theory through a constant dialogue between me, the researcher, and the collected data, as well as between the theoretical thoughts and empirical evidence, in which the story of social interactions during shopping emerges. Simply put, GTM's main purpose is to develop an empirically "grounded" theory (Glaser/ Strauss 1988).

In this study, the first core concept was constructed to represent the research subjects' (primarily the salespeople, but also the observed customers') concerns. After the core concepts were defined, attention was turned towards an understanding of why and through what kinds of social practices stores' owners imbue their businesses with additional meaning (Rosenbaum 2006: 64; 2007).

The fieldwork itself followed Ronald Hitzler and Anne Honer's ethnographic "life world analysis" (Lebensweltanalyse; Honer and Hitzler 1984; 1986; 1991; 1995; 2003), which emphasizes the inner perspectives of the observed social life worlds of local businesses. This approach helps to reveal not only inner perspectives, but 
also the inner micro-logics and micro-geographies of everyday life ${ }^{104}$ and to focus on those social practices in local businesses that generate and nurture them.

Originally, the project was conceived around a comparatively closed research question (and thus a more "classical" sociological framework) of "How and in what ways do local businesses contribute to the creation of local social capital, and on a neighborhood level, to social cohesion?" The initial idea was to frame and explore social interactions during shopping through the lens of social cohesion (Durkheim 1988) and social capital (cf. Putnam 1995, 2000; Coleman 1988; Bourdieu 1986) - both prominent and popular theoretical concepts in the field of sociology. During the course of my empirical inquiry, I soon discarded them in favor of a more open-ended and impartial methodology in order to avoid both a narrow focus on these social interactions as a singular type of social practice and the quite normative view of these two concepts on social life in urban settlements. However, the research on social cohesion and in particular on the different definitions and concepts of social capital during the first four months of my research still proved to be fruitful for the conceptual structure of this story and revealed possible directions and maybe so-called grand theories, with which the empirical results could be interpreted. In addition, it could be conceivable that one of the core concepts of the empirical data is local social capital.

To return now to GTM, there are two main variants that have been developed since the 1960s: Anselm Strauss's (1998 [1967]) pragmatic version, rooted in the epistemological and socio-philosophical tradition of American pragmatism of the Chicago School; and Barney Glaser's (1978) more "empiricist" or more inductively working version, popularized by the so-called "just do it!" positive-functionalist school at Columbia University (Strübing 2002: 320). Despite their difference, the crux of both types of Grounded Theory remains the constant repetition of the recognition-steps of induction, abduction, and deduction, which generate, test, and eventually discard and/or modify ever-new theories and hypotheses (Strübing 2008).

Working within the specific iterative mode offered by the GTM, with a view to a maximum of analytical openness, this research more closely follows the approach and research tools offered by Anselm Strauss' version of GTM with an "activist, through action, i.e. working, revealed meaning of objects" (Strübing 2008), and links it to the idea of the businesses as the local spaces where (different) social worlds might intersect, be maintained or nurtured, or be newly generated. In line

104 "The World in the City" - the focus of the International Graduate Program at the Centre for Metropolitan Studies at the Technische Universität Berlin - was interpreted in this thesis as including the numerous and sometimes overlapping small (social and/or ethnic) worlds that can be linked to specific social and physical places. 
with the ethnographic research approach (which also stems from the Chicago School), these approaches help to describe the overlapping and new generation of social interactions within the small social life worlds as densely as possible. In the course of this process, description and analysis are not treated as dichotomous poles, since the act of describing (both in my observation protocols and data collection, but also in the descriptions given by the interviewees themselves) is inherently a process of understanding that offers in its final written iteration an explanation of the observed social processes.

Within life world analysis, the second intrinsic research process aims to describe (and thus explain) small segments of social experiences in order to discover, describe, and analyze as many aspects of so-called "part-time world of senses" (Teilzeit-Sinnwelt by Hitzler/Honer 1995: 382) as possible - each with its own rules and routines, which, put together, create everyday life. As such, small social life worlds are the most effective way to interrogate the small social formations of a socially-constructed world of experiences generated by the everyday practices of shopping (buying and selling), consuming, spending leisure time, and working. The underlying assumption for this project is then that businesses represent one location where different social life worlds are concretely experienced and (re-)constructed on a neighborhood level. Only by focusing exclusively on the subjective perspectives and interests of the research subjects (and not on my interests as a sociologist), is it possible to capture these small social life worlds. Put in other words, the main methodological task was to change perspectives and discover the research subject's world through their eyes. This fundamental change of perspective affects not only the analysis, but also the data collection, forcing a reconstruction of the research subjects' subjectively constructed social life worlds (cf. Hitzler/ Honer 1995).

Ultimately, GTM and life world analysis (as opposed to other qualitative social science methods) share many points of emphasis: the expectation that the relationship between researcher and research subject will continuously evolve; the processes of describing and explaining; and the parallel, mutually interdependent, and ostensibly perpetual, sequences of data collection, data analysis, and theory generation. Through this dialectical process, a theory is developed that is at once heavily influenced by the subjectivity of involved actors and specific conditions, but also can take the form of a general social theory (Strübing 2008: p 14 f.). For instance, the first interview and first two days of observations in and around the flower store (the first empirical case) pointed to the themes of emotional and social support, mutual assistance, business-friendships, and sense of community as created in the business. These emerging themes were then tested and contrasted with, expanded, limited, or rejected with each data acquisition, becoming 'thicker' or 'stronger' with the addition of detail and dimension. For this specific sampling 
process in GTM, no special accommodations were made for any paradigmatic position or uniqueness of the data to be collected, or principles of representativeness (Strübing 2008: 30). The main features of ethnographic life world analysis and of GTM complement each other since they mutually reinforce their explorative and investigative nature and support the reconstruction of the (assumed) little social life worlds in and around Karl-Marx-Straße's businesses.

The highlighted aspects of the intertwined approaches of GTM and life world analysis also help to understand the role of my own person in the progression of my ethnographic field work, which was neither objective nor external, but influenced my research subjects throughout the observational process. The combined approach helped to disentangle the researcher's own (subjective/biased) positionality while working in the field. Working ethnographically de facto involves the researcher acting in (an on) a concrete social environment, so it was imperative to consider my position as an immediate participant throughout the research process.

My own positionality became more apparent the more time I spent on KarlMarx-Straße, and the greater number of interviews and observations I conducted. First, the majority of Karl-Marx-Straße's businesses are operated by men, who often cater to a predominantly male clientele, or are engaged with more men than women during certain times of the working day. Second, the street hosts a lot of businesses operated by people with a so-called migration background. Whereas some stores cater to specific age or lifestyle groups, others (often framed as "ethnic businesses") predominantly welcome people of the same (regional, national, or city/village) origin as the owner and/or selected employees, and where the conversations take place in foreign languages. The named examples represent spaces in which my appearance was often conspicuous or exceptional, and by entering some of them, I immediately drew attention to myself. With every interview and observation, it became clearer to me how much my personal attributes mattered in the conduct of fieldwork.

By way of example, I gained my first exploratory expert interview with relative ease due to my privileged position as a formal member of the academy, my German ethnicity, social background, my (professional) language skills, field and interdisciplinary professional knowledge (in this particular case, the logic, the vocabulary, and rhetoric of urban planning) and Caucasian appearance, with which I gained a great deal of trust and internal information that was not necessarily accessible to others. In contrast, during other moments in the data collection process, exactly these same attributes became obstacles to my research: In particular, my profession, my gender, my age and physical appearance led to incidents of distance, mistrust, 
and distrust ${ }^{105}$ (Sztompka 1999). Many of the business people I approached were skeptical about my intentions and the purposes for studying them; most of them suspected me of working for the tax authority or for a new or soon to open competitor (which paralleled many owners' fear of rising rents and eviction, or of having the whistle blown on underhanded sales tactics or tax fraud).

In some of the businesses, if the conversational or service language was for instance Turkish, Arabic, or Polish, I could only observe the types of interactions, the gestures, tones of chats, and facial expressions. In parallel, due to my Caucasian appearance, people often observed me observing them, no matter how much I tried to play the role of regular customer. Further, some customers - most often men - were visibly disturbed merely by my presence. ${ }^{106}$ However, in the context of my own buying, ordering, and consuming practice, none of the businesspeople paid more attention to me than to any other unfamiliar customer, which, for instance, mimics their routinized interaction with unacquainted customers with eventually diverse ethnic backgrounds.

My own and the interviewees' positionalities also played a role in how store owners and planning experts framed and described the street's users: For instance, the urban planner in the local planning department assumed that I favored the same type of new businesses that he welcomes and enjoys in the area, with a preference for the same aesthetics and offerings. This was one reason why he, for instance, felt comfortable with talking openly about the renewal plans to get rid of some of the current (migrant owned) businesses.

In part, my early research on the commercial and residential structures of KarlMarx-Straße, conducted before entering the field site, colored my first perceptions and impeded the required change of perspective. The often stereotyped perspectives of store owners and planning experts shaped my initial observations of customers, local residents, and street users. To move beyond frames located in the socio-economic and demographic statistics of Neukölln, it was crucial for me to encounter every single individual as a total stranger and not to make any assumptions based on their physical appearance. Fundamentally, the challenge was to see the world through my respondents' eyes. From the first observations and interviews, it was obvious that each business attracts, receives, and serves a diverse group of customers,

105 Social trust is defined as the belief that others in society can generally be trusted, and leads to positive outcomes in exchange situations - such as the participation in an interview. In contrast, in a situation with a lack of clear expectations, one hesitates to commit oneself; creating a situation more of mistrust, where trust and distrust are suspended or where trust or distrust are withdrawn (Sztompka 1999: $26 \mathrm{f}$.).

106 This is also the reason why I either switched off or did not use my recorder at all during conversations with customers. 
varying by ethnicity, age, income, and gender. It was a continual challenge not to enact and fix constructed identities based on these ethnic, gender, or social status categories in my fieldwork (following Neal et al. 2015). While at the research sites, my field notes on social practices and interactions revealed differences between or commonalities among the observed people (and me). However, memo writing removed much of the nuance, reducing individuals to their most visible characteristics, and thus highlighting these differences on a (visible) basis. Looking at the physical (e.g. skin or hair color) and the cultural (e.g. dress and accessories, spoken language or dialect) aspects of a person is neither enough nor appropriate to ascribe an ethnic or lifestyle identity. It reduces individuals to racialized sets of identification. Without interviewing people directly and asking them about how they construct their identity and background, the observer has only unverified and highly subjective impressions. Thus, my fieldwork was marked by many efforts to avoid stereotyping on the basis of the interviewees' and my own observations, yet it leaves me with an uncomfortable concern that my insights might still be influenced to some degree by an objectified and biological-essentialist seeing (Neal et al. 2015: 467).

Conversely, the direct, highly participatory, and dialogic engagement of fieldwork often helped me to avoid the ethnographic gaze. My study goes to "the thing itself," directly focusing on the social practices of the storeowners in an effort to corroborate - or set aside -- my initial impressions, public statistics, or official characterizations of the neighborhood (cf. Valentine 2013).

\subsubsection{Inquiry Methods: Interviews, Participant Observations, Secondary Material}

My inquiry into the social and material aspects of the businesses along Karl-MarxStraße and their role in local social life used a multi-method or triangular approach, involving in-depth interviews and participant observation in the sampled business sites and expert interviews with the three main actors of the local urban development programs. The study's mix of methods thus attempts to generate a more attentive, dynamic and reflexive practice that privileges the interviewees' and other co-present participants' voices and social practices, not the researcher's preconceptions. While larger data sets were mined on the meso-level for the historical and current socio-demographic and economic portrait of Karl-Marx-Straße, providing "a lens on patterns of locality" (Hall 2015: 27), micro-level research revealed the nuances and dynamics of the everyday interactions and related social practices in the businesses. Only ethnographic work - by means of in-depth interviews and 
participant observation - can illuminate the local social life in these urban settings, especially in the ostensible final frontier of micro-geographies of local businesses. This multi-method approach thus allows the researcher to live up to the "topological complexity of lives lived within and between a number of urban locales" (Hall 2015: 27) - the businesses, the wider street and neighborhood, the city and beyond.

\section{Interviews}

The one-to-one interviews with store owners and employees took the form of "shopping interviews" - a play on "walking-interviews" (Neal et al. 2015: 466) or "go along-interviews" (cf. Kusenbach 2003). Concretely, this meant that during the interview, staff and owners continued to serve customers, which increased the potential access to some of the ephemeral and reflexive aspects of lived experience in situ (Kusenbach 2003). They also showed me around their business, pointing out important people, tools, artifacts (Reckwitz 2003) or locations within the business that have a special meaning for them or for selected customers, or for interaction between and among them. The interviewees were either fully focused on the interview or on the individuals who approached them - customers or colleagues, serving or replying, opening the interview or discussion to them, but also readdressing the interview when they were gone, or cutting them off to continue the interview. With the exception of the flower store owner's mother who listened and interjected several times, in no other interviews, was anyone else sufficiently involved to disturb or change the course of the interview or the owners' answers.

Anonymity was offered to all interview partners. In practice, however, all gave their informed consent to use their own or their business' names. While this study uses pseudonyms, such as café I or main café, or avoids names altogether, the detailed information provided here about the street, the businesses, and their staff still would enable the determined reader to identify the research objects and subjects. ${ }^{107}$ For instance, the maps of Karl-Marx-Straße can easily be evaluated for postal codes and house numbers, and from that basis, the vast array of the working individuals can be found as well. As representatives of their urban planning office or renewal program, the names of the interviewed local officials and their programs could not be anonymized.

The interview guidelines had a more or less standardized design, with the main focus on the self-description of their everyday work on Karl-Marx-Straße, interactions with customers, and "business survival strategies," and perceived neighborhood changes. Starting with a simple question about when the owner(s)

107 For the publications all additional information and in particular the locational information on the businesses are altered or cut out. 
began operations, it was easy to lead the conversation to topics of change, role for the neighborhood, and if they offer "more" to their customers, their motives for doing so, and to their relationships to (regular) customers and other business people. The interviews with the owners were conducted exclusively during business hours and while the owner of the pharmacy and butcher's shop took me to their back offices, all the other interviews took place in the sales spaces, behind or across the counter. However, owners suggested interview times during hours when business is usually slower. Even when interviews were conducted in the back, conversations continued in the front rooms. Sometimes staff also directed me to the business entrance and outdoor spaces, most often to the front sidewalk in order to point out changes, people or places. And again, since the interviews were conducted during operating hours, I could immediately match the narratives of the owners about selected customers or employees to both their actual behavior towards them and to my own observations (e.g. style, personality, frequency of business visits, preferred goods or services or seats, etc.). The primary intention was to match happenings and utterances contemporaneously, to hear and see more and "better," to absorb the multiple relationships and connections between the interviewee, the other individuals present, the space, and me as the researcher. The ethnographic work was repeated; these regular observations and conversations in the businesses allowed for a further engagement with the spaces' atmospheres, practices, uses, daily rhythms, sounds, and smells.

At the center of this research design was the attempt to develop a familiar but non-intrusive relationship between the interviewer and interviewee (Neal et al. 2015). The relationship to the interviewed store owners was based on the repeated contact and dialogue during the field visits, but also on staying in touch with the interview partners outside of the visits and observations in and around their stores. By means of "just being in" the locations and in doing the interviews during the normal opening hours, the businesses with their concrete spatial materiality were themselves embedded in the research process and design.

The in-depth interviews' guidelines and conduct used elements of narrative, focused, and semi-structured interviews, but also of a problem-centered interview, with plenty of space for biographical anecdotes. Due to the dynamic and often conversational style that also allowed for the involvement of material artifacts and moving around or changing position or space, even those owners who showed the most distrust before or early into the interview seemed to forget theirs suspicions, comfortable in their familiar setting and their routine roles as businesspeople. The development of trust and ease was also enabled by my efforts to immerse myself as much as possible in the field, developing "embodied ways of feeling, seeing and understanding" (Gieryn 2006: 6). 
The fieldwork began in late 2012. Although the first exploratory interviews with the head of the urban planning office in charge of City Management in and around Karl-Marx-Straße and the first store owner interview were conducted in December 2012 , the complicated sampling process took time to complete. Beginning in autumn 2012, I wrote letters and emails to around 30 businesses on and near Karl-MarxStraße, also calling several times and dropping by half of them. Unfortunately, fewer than expected agreed to take part in the "formal" interviews. Ultimately, eight business people took part in the formal in-depth interviews (between 1.5 and 3 hours in length), whereas four owners agreed to talk to me only informally. Ultimately, it was possible to speak with all of the businesses in the additional cases described in Chapter 5.6., but most of the data used comes from interviews of the core sample. In those cases where the opportunity for a comprehensive interview was limited, I tried to observe more comprehensively. Although it was possible to describe the social practices of customers and salespeople in the businesses in detail, it was hard to measure the social meaning of shopping in these places to the customers observed, which was unsatisfying. In addition, without being able to interview the customers, my descriptions of age, socio-economic status, ethnicity, place of residence, and real motivations must necessarily remain superficial and speculative. This gap could be bridged somewhat by talking informally with individual customers and by listening to their conversations.

Concerning the customers, though these methods allowed me to gain insights from approximately 15 shoppers in different stores, the inability to conduct formal interviews together with the presence of other people, language issues, and the press of time limited what could be learned. Nevertheless, to the extent they could be captured, these conversations and social practices were noted in my observation protocols, often in very detailed and dense way. Particularly important were their motives for spending time in or frequenting certain businesses and what they expect to happen there.

\section{Participant Observations}

The second main research tool applied was participant observations in the businesses. Unlike everyday observation (so-called "people watching"), scientific observation is characterized by a special focus and methodological control. The basic idea of qualitative observation is that the researcher - through the proximity to the research subject - is able to capture the inner perspective of the observed subject. Participant observation is particularly suitable when the subject is embedded in a social situation, when the subject area is difficult to see from the outside, and whenever the research question has a more exploratory and theory- or hypothesis-generating character (Lamnek 1993). These aspects apply to the current study about Karl-Marx- 
Straße's businesses, where the owners and their staff are inextricably linked to and embedded in the social situation of their businesses and these businesses are in turn embedded in larger social and commercial processes of the street.

The combination of participatory and non-structured observations was once the exclusive purview of anthropology and ethnology. But urban studies, where the city becomes the study's object and venue at once and where the city acts as the "empirical referent for analysis and the physical site where investigation takes place" (Gieryn 2006: 6), and, in particular, for an ethnographic urban studies study, such as the one at hand, have also become appropriate venues for participant observation (Gieryn 2006; Lüders 2008). Finally, participant observations also represent the most appropriate and fruitful method for my inquiry of urban social life, since the significant feature of the qualitative observation is the use of the natural world of the subjects (Lamnek 1993).

During participant observation, the data is collected in the process of by participating in natural situations and in face-to-face interactions. Hence, through the direct experience of situations, aspects of acting and thinking become observable that would not have been during discussions with experts, the owners, or other groups, or by reading documents on these interactions or situations. Simply put, the characteristic of this method is the personal participation of the researcher in the interactions with people, but applying participant observation is also a switch to and from the field, from proximity (participation) to distance (observation). Thereby the distance is essential to enable the necessary scientific reflection to analyze the observed interactions (Lüders 2008; 2001).

The observational criteria are developed either before entering the field and/or throughout the research process. After some preliminary "test" observations but without a fixed set of observational categories, I sharpened the categories with each additional observation. However, each of the observations had a different focus. Therefore I did not follow a general observation category catalogue until the end of the fieldwork. In the beginning, I tried to make sense of the spatial qualities in the business and at what concrete points they enabled interaction or increased the likelihood of interaction between acquainted or unfamiliar people. Subsequently, my attention was drawn to the spatial qualities as front or back stages (Goffman 1959; 1963), spaces that "belong" to the customers or employees, or spaces that blur these lines. I also looked at background features, such as music or TVs playing, smells or noises, the overall temperature, and atmosphere (following Kazig 2007; 2012). Following Reckwitz (2003; 2003) and Kazig (2007; 2012) and their praxis-oriented perspective, I understand shopping or consumption as a practice or set or chain of practices that can be realized in numerous ways, including the gathering of information before entering the store, the actual visit and consultation 
in the store, the purchase and immediate consumption, or transportation of the purchased goods to the customer's home. This is linked to the so-called shopping atmosphere, because "the subjective mood of a person can change depending on the surrounding" and "this change in mood can be expressed in the mode of attention, motor behavior, or emotionality" (Kazig 2012: 64). Simultaneously, the surroundings, in which shopping takes place, have different qualities. These can affect the customer's mood, and the completion of the purchase, shopping, or consumption act in many ways. The focus in the observations was thus also on the atmospheric characteristics of the businesses.

Beyond material and interactive qualities, the focus shifted in the second phase of observation to the people in the store, their physical appearance, and social behavior. These observations were more interested in social practices and their carriers (Reckwitz 2002; 2003), their performance (Goffman 1959; 1963), and less in the concrete spots or micro-geographies of these practices (since they were the focus of the first observational phase), before moving finally to an examination of the social practices/ actions, behaviors and the impact of these. Just as in the interviews, the main challenge was not to describe the actors in a stereotyped, racialized, or biological-essentialist way.

Generally speaking, my individual observation methods can be distinguished along the following lines: Open versus hidden observations - the owners knew of my presence, but not the customers. Whenever someone noted my longer-than-usual presence in the business, I introduced myself as a researcher working on social practices in Karl-Marx Straße's businesses. Participatory versus non-participatory - I interacted with the researched subjects and within in the research subject. I actively participated in the socio-spatial setting, performing or carrying out the same practices as other customers during the observation. The observations did not follow a structured and detailed observation scheme, but were structured - in those cases where field notes were taken - after the visit, comparing the notes and contrasting them to previous observation protocols (following the GTM idea of looking for minimum and maximum contrasts in order to underpin or discard the emerging themes and aspects) (Bortz/ Döring 2013). I was present in all businesses for a minimum of five separate occasions and even more often in the gastronomic businesses with seating. Seating facilitated observation and immersion in the field, whereas in the other businesses "hanging out" was much more complicated after the purchase and eventual consumption.

In those cases where the possibility of comprehensive observation was limited, I tried to expand and refine the interviews, reaching toward a greater level of detail and narrative from the interviewees, focusing less on knowledge oriented questions, interviewing and talking to them during shopping interactions or normal 
business operations. Furthermore, my interviews took place during all opening hours: weekdays and Saturdays, morning, midday, afternoon and evening hours, as well as nights for the bars and restaurants. ${ }^{108}$

Bortz and Döring's (2013) six typical steps of qualitative observation guided the conduct and analysis of the participant observations:

The first phase consisted of planning and preparing the observations and time in the businesses. During this phase, I tightened up the investigation topic, tried to operationalize my research question and to collect first experiences in the field, looking for a suitable place, table, corner, as well as most important actors in the business. The second step was to enter the field, where I also addressed the field subjects and expanded my social contacts to recruit more interview partners (in and outside of the businesses) and developed first thoughts on the ethical issues and risks of losing the distance due to the potentially confused role as a dedicated and committed participant observer. The third step was to reconsider my behavior in the field. Here, I tried to constantly rethink my own role and my "effect" on the social interactions that are observed, supported by the fourth step of writing a field diary. Unfortunately, I did not manage to write it in a consistent, extensive, and detailed way as would be required in the classic style of qualitative observation. The notes and documentation materials were complemented by photographs, if the situation allowed. Hanging out in the businesses was accompanied by different degrees of difficulty, not only in regard to taking notes. Particularly the very small businesses, the very busy ones, and the ones where it became clear that I was not a regular or where only the "real" daily customers stay for a chat, whereas others enter the business only briefly for the purpose of buying a certain good or product (e.g. in the butcher's shop), complicated observations. ${ }^{109}$ For most stores, I also had to consider the so-called exit from the field as penultimate step. Having been a regular customer for weeks or months in some of the businesses, certain salespeople or waitresses noted my absences and asked about my whereabouts on certain days when I did not show up as before. It was not easy for me to tell them that the study was almost over and thus there were fewer opportunities for me to spend as much time on Karl-Marx-Straße, but that I would try to come back as

108 Sunday is not a shopping day in Germany. None of the sampled businesses is open on Sundays, but some bakeries, flower stores, and kiosks also open on Sundays in Neukölln and Berlin.

109 Despite my aversion to constant consumption, I spent a large quantity of money buying many small items for fear of "discovery" or exploiting the staff; although I told the owners and all other people who asked that I was doing research on Karl-Marx-Straße. Still, each of the observation days cost approximately ten Euros. 
often as possible, thereby gradually preparing my field exit. ${ }^{110}$ The sixth and final step for participant observation is to evaluate the gained data across and within the observation notes. In order to do so, I looked first for regularities and rules, which were then summarized descriptively. Similar themes were represented as accumulations of the information in a matrix of topics, also linked to the transcriptions from the interviews.

\section{Expert Interviews}

For urban studies (and particularly the planning disciplines), expert interviews represent one of the most common access points for research: Because they hold formal positions that convey the prerequisite of certain competencies and expert knowledge, urban researchers often seek such experts for the provision of information on a certain topic that is not accessible through other methods or individuals (who are understood to lack the necessary expert knowledge). Although it is assumed that all people are experts in certain things, the subjective ascription of an expert status to a single person complicates the selection of the appropriate 'expert' for the research in general. There is no general expert status - if someone really is an expert is an empirical question that must be refined and critically reflected upon over the course of and after the interview in question (Eckardt 2014: 149). Hence, I selected three experts on the basis of the assumption that each of them knew something about urban renewal and commercial development on the street that was inaccessible to me otherwise. The three experts showed competency on technical processes and interpretative knowledge in their designated fields. As such, their expert knowledge should not be understood as systematic or reflective of specialist knowledge, but rather as practical knowledge, whereby the expert has the opportunity to implement their ideas and orientations (Eckardt 2014).

The main fields of action for the interviewed "experts" were the concrete planning processes and physical reconstruction of the street (including the development, implementation, and supervision of individual measures and their promotion and communication), commercial development (including the development of a new street image as a shopping, leisure, cultural and tourist destination), the promotion of the street and its commercial changes, the support and management of the commercial facilities, and the lastly, urban renewal as the combined umbrella program and processes.

110 For some of the businesses and staff members, I deeply regret of not being able to come back as often as I would have wished, having built relationships with them and having enjoyed the inclusion in their small social life world at least for the time of the field work. 
Since all involved agencies have webpages - in line with their aim of presenting a transparent and public urban development - I searched for those individuals who hold formal positions with decision-making power for those planning aspects that could most affect the businesses and business owners' everyday practices.

The expert interviews took place in their respective offices in Berlin, two of which are located on Karl-Marx-Straße, each lasting between an hour and two. The guidelines (see attachments) followed the same principles as the guidelines for the store owners, allowing for personal narratives, anecdotes, and the involvement of material (e.g. published material, such as the tourist and shopping guides, which were often included to underline the success of their work or the material output of the programs). I purposefully tried to cover similar thematic blocks in order to compare and contrast the different experts' statements in the analysis.

Before meeting with them, I contacted the three experts via regular mail, email, and telephone, but since all three had worked together with academics and Technische Universität Berlin researchers before, they seemed familiar with the inquiry, the interview course, and general situation. All immediately agreed to meet. However, while the City Management head suggested a meeting in the week after my initial request in 2012 and before having entered the field, the two other planners postponed the interview dates several times. ${ }^{111}$ In addition, they seemed to doubt my own expert knowledge (having worked in urban planning before) and tended to explain basic planning information to me that sometimes interrupted the course of the interview. On the other hand, they were highly skeptical about the research project and applied methods, but also the validity of doing research on businesses they considered of being either "low quality" (urban planner 1. 177) or unlikely to survive in the long run. Just as the in-depth interviews and participant observations, the interviews were recorded, transcribed, and I took notes on the setting and progression of the interview.

\section{Additional Data}

Additional data was collected from maps, statistical material produced by the local urban renewal programs, national, city, and district census data, the renewal and urban development plans and their other publications, promotional leaflets and publications from the businesses themselves, policy documents, and zoning laws as well as newspaper and magazine articles.

111 However, the head of the City Management knew me from a previous collaboration with the Senate for Urban Development, in which we both participated, which is probably why she agreed to meet much faster than the two other planners. 
Before entering the field, but also in the course of the field phase, I constantly collected and re-verified collected additional data. Once a week between January 2013 and January 2016, I searched online for new newspaper and magazine articles about Karl-Marx-Straße, the Active Centers and City Management and Aktion KarlMarx-Straße programs, new or closing businesses in the neighborhood, as well as neighborhood events along the street. In addition, I researched the programs' homepages for new publications and announcements every three weeks and collected all their material, combining the material with my own and other local and city-wide actors' comments and thoughts about them.

The statistical material and maps were used mainly in the beginning of the fieldwork and to make sense of the neighborhood's residential and commercial composition before the ethnographic work began. Fortunately, I convinced the head of the City Management program to send me the preliminary report on Karl-Marx-Straße, including an examination of the customers and their origins (within the district, the city and beyond, their shopping patterns, and their likes and dislikes about Karl-Marx-Straße) and an almost complete list of the existing businesses in 2011 with the name of the owners, type of business, and if available building owners and length of business residence (this list is available to the public). These documents helped a great deal in the development of a first grounded sense of the street, its residential and commercial past, and the dominant current urban development issues.

The majority of the information on the local urban renewal programs was gleaned from the programs' own homepages and the Senate Department for Urban Development and the Environment with their numerous documents on the local processes and planning visions. ${ }^{112}$

Beyond the general information on Karl-Marx-Straße' users and customers that I gained out of the preliminary examinations of the City Management and Aktion! Karl-Marx-Straße and the umbrella program Redevelopment Area Karl-Marx-Straßel Sonnenallee, I also followed randomly chosen visitors of Karl-Marx-Straße on the street's main strip between the metro stations Hermannplatz and Karl-Marx-Straße, noting what routes they took, where they ran into other people, where they stopped for a break or to meet others, which stores they frequented and for what product/ service. Furthermore, I also spent four afternoons in 2013 and 2014 walking up and down the street and the shopping mall, taking notes on physical, commercial, and demographic changes as well as on the wandering construction site.

112 See their publications on: Berlin- das Hauptstadtportal (n.d.). Pressemitteilungen, http:// www.stadtentwicklung.berlin.de/, accessed 03/16/2016. 
The combination of this diverse material along with the in-depth interviews and observations allowed me to research the street and its businesses from very different perspectives and thus to cover the manifold dimensions and often simultaneous and linked processes occurring therein, and thereby to do justice to the complexities of ordinary metropolitan social life.

\subsubsection{Design of Data Analysis}

The data gathered within GTM becomes increasingly focused as the researcher engages in data analysis while collecting further data. Again, the simultaneous involvement in the data collection and data analysis aims to develop a theory (Charmaz 1996: 34). Furthermore, with this inductive method, the data was generated in concert with the interviewees (or observed people), always trying to work out the underlying structures of meanings for their behavior and statements. Permanently linking the emerging theories, the sensitizing concepts, and the theoretical concepts and the data, my research attempts to make these meanings explicit. The emphasis on what people do and say and how it "leads to understanding multiple layers of meaning of their actions" (Charmaz 1996: 35), comprising, in this case, the store owners' stated explanations of their actions, the unstated assumptions about them, the intentions to engage in them, their effects on other people (particularly the customers) and the consequences for further practices and relationships (cf. Charmaz 1996).

All interviews were transcribed in detail, including non-verbal expressions such as laughter or groaning, but without following a hermeneutical, socio-lingual, or phonetic transcription system (with the help of the transcription program F4). Following a GTM approach, the majority of interviews were transcribed immediately after the interview and partially coded for emerging themes, before searching for the next case. The purpose of coding is to make the major themes of the emerging data evident. I therefore created codes in the course of studying the data that acted as the pivotal link between the data collection and an emerging explanatory hypothesis (Charmaz 1996: 37).

After the first two interviews and transcription $s^{113}$, the search for contrasts and similarities, as well as for correlations and other linkages began in earnest. This process and the line-by-line coding continued for all in-depth interviews with store owners until a sufficient density of dimensions, characteristics, and manifestations

113 When interview partners are cited, I name the transcription line numbers, even though the transcriptions are not attached in this book. 
were found for each emerging theme. Manual coding thereby helped to curtail the number of categories (a common symptom of digital GTM coding programs). Simply because of the limited number of available colored pencils, I decided to develop no more than 25 categories, out of which I extracted and worked out four main themes or main codes. With each new interview, its transcription and coding, I searched for new insights or manifestations until the "point of saturation" (Glaser/Strauss 1967; 1998) was reached.

Although a digital program might have allowed for a more comprehensive overview of all the early codes, their development, and combination with the main codes as well as acting as an overview, manual coding allowed for a more integrated approach, analogous to the ideas of Strauss and Glaser, where data generation and theory generation are deeply intertwined and the latter emerges step by step out of the newly generated or updated data (Glaser/Strauss 2009; Strübing 2008). Although it is easier to find individual references to "belonging," "home," "community," "gentrification," "neighborhood," etc., with a coding software, manual coding allowed for the discovery of more subtle references, relationships, correlations, tropes, indirect metaphors, allusions and ambiguities, elucidating the subtleties and subtext of the store owners and renewal agents' narratives about the neighborhood and the street's urban renewal, vision and physical transformation. Since these terms are not all part of everyday German speech and imply a sense of commitment and emotion that is often too intense for a description of the stores' micro-processes, it seemed easier to dismantle the metaphors and allusions while interpreting them with manual coding. The term "cell phone stores," for instance, carries numerous meanings for the urban renewal agents, all with a pejorative connotation, but which are individually used for very different purposes, such as describing the neighborhood's past, an unsuccessful commercial structure, a store that will not survive, store owners that were unwilling to cooperate, store owners that were incompetent business people, or stores the urban renewal agents would never frequent. Manual coding helped to dismantle the different structures of meaning that turned out to be more or less the same for all three urban planners, for instance.

The main questions for the coding of the interviews and observation material were: What is going on, what are people doing, what are people saying, why are these practices and statements taken for granted, and how does the context or the structural background affect these actions and statements Later, I searched for the underlying or explicit processes and their cause, consequence, actors, and conditions.

After each transcription, the texts were searched for information that was not available through other sources, but more importantly for the subjective structures of meaning for each interviewee. Basically, how did they assign meaning to their everyday practices in the business and their role in their business? I thereby tried 
to reconstruct these meanings, the social contexts in which they developed, and any similarities, differences or correlations/ linkages to previously generated data.

In a parallel process, since participant observations and interviews took place during the same time window (between November 2012 and November 2015, often on the same day as the interviews), the observation protocols as texts were coded in the identical way.

Finally, from the many emerging themes and categories, the four main themes or codes that evolved out of the combined data were: the material qualities of spaces that foster interaction; the social practices (mainly of stores owners) that support interaction and generate ties; the social practices of store owners which "make the place" of the business as well as of the street; and broadly said, the notable influence of neighborhood change on social life in and around these businesses.

These themes are clearly linked to the sensitizing concepts and the literature review before and during the empirical research phase. However, the data analysis's open and explorative design should have enabled further themes unrelated to the sensitizing concepts to come to the fore. Lofland $(1972 ; 1973)$ and Goffman's $(1959 ; 1963)$ ideas about public behavior helped to disentangle social practices for the business (as more intrinsic, less strategically performed practices or business survival strategies) and social practices for individuals (owners and customers, as more routine daily and less strategic social interactions).

By contrast, the main themes emerging from the expert interviews centered on the ongoing urban renewal process and the role of store owners therein. Hence, this data analysis did not generate a new theme or code, but rather condensed the fourth main code and added tangible manifestations and features.

Hence, the five main steps of GTM inspired the entire empirical inquiry and analysis process, even if not all ideal-typical steps were taken. The research started with theoretical sampling - switching between the data and its interpretation and links to the sensitizing concepts and new emerging theoretical concepts - , and went on with theory-oriented coding - linking and integrating the concepts and categories -, and permanently compared the new and previously generated concepts, supported by the memos that were written in between the research steps on each case. I also looked for the relational patterns between the data and concepts, but also between the inquiry, the coding, and the memos.

Memo writing formed a crucial part of the process, as an intermediate step between coding and a first data analysis, helping to elaborate the social processes, correlations, practices, conditions, and contexts as well as the assumptions that were incorporated into each code. Therefore I constructed charts that categorized interview quotes under each of these aspects as well as under the theoretical concepts,' in anticipation of the findings chapters preparation (Charmaz 1996: $42 \mathrm{f}$.). 
These charts also supported the interpretation and writing process, since interview quotes were already at hand for each subcategory of the main codes.

Ultimately, most material was coded for dimensions of material aspects (conceptualized with help of Oldenburg's third places) and for the social aspects important for the generation of in-store interaction, combined with the role of store owners for the street and neighborhood (conceptualized with the help of Jacobs' public characters) and for neighborhood change as setting the framework within the three latter dimensions occur (conceptualized with placemaking).

Before moving to a discussion of my findings, the next chapter discusses the businesses in an explanatory and detailed way, drawing on interviews, observation, and secondary literature.

Open Access This chapter is licensed under the terms of the Creative Commons Attribution 4.0 International License (http://creativecommons.org/licenses/by/4.0/), which permits use, sharing, adaptation, distribution and reproduction in any medium or format, as long as you give appropriate credit to the original author(s) and the source, provide a link to the Creative Commons license and indicate if changes were made.

The images or other third party material in this chapter are included in the chapter's Creative Commons license, unless indicated otherwise in a credit line to the material. If material is not included in the chapter's Creative Commons license and your intended use is not permitted by statutory regulation or exceeds the permitted use, you will need to obtain permission directly from the copyright holder.

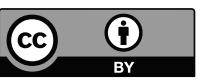

